\title{
Design of A Pentagon Microstrip Antenna for Radar Altimeter Application
}

\author{
K. RamaDevi ${ }^{1}$, A. Mallikarjuna Prasad ${ }^{2}$ and A. Jhansi Rani ${ }^{3}$ \\ ${ }^{1}$ ECE Dept., Pragati Engg. College, Kakinada, A.P., India \\ ${ }^{2}$ ECE Dept., JNTU College of Engineering, Kakinada, A.P., India \\ ${ }^{3}$ ECE Dept., V.R. Siddhartha Engg. College, Vijayawada, A.P., India \\ \{kolisettyramadevi, a_malli65\}@yahoo.Com, Jhansi9rani@gmail.com
}

\begin{abstract}
In the navigational applications, radar and satellite requires a device that is a radar altimeter. The working frequency of this system is 4.2 to $4.3 \mathrm{GHz}$ and also requires less weight, low profile, and high gain antennas. The above mentioned application is possible with microstrip antenna as also known as planar antenna. In this paper, the microstrip antennas are designed at $4.3 \mathrm{GHz}$ (C-band) in rectangular and circular shape patch antennas in single element and arrays with parasitic elements placed in $H$-plane coupling. The performance of all these shapes is analyzed in terms of radiation pattern, half power points, and gain and impedance bandwidth in MATLAB. This work extended here with designed in different shapes like Rhombic, Pentagon, Octagon and Edges-12 etc. Further these parameters are simulated in ANSOFTHFSS $^{\text {TM }}$ V9.0 simulator.
\end{abstract}

\section{Keywords}

Rectangular patch, Circular Patch, Pentagon shape, impedance bandwidth, radio altimeter etc.

\section{Introduction}

A radio altimeter is a device, which is used to measure a low altitude or distance from an aircraft or spacecraft to ground surface or to a sea level. This distance is calculated under the craft in vertical direction. Radio altimeter is a part of radar. The working principle of radar is, it transmits radio waves towards ground level or sea level and receives an echo signal after time duration. This value of time is depending on speed of the vehicle and height between craft (air or space) and ground. Here an antenna places a pivotal role to transmit the radio waves and receiving of waves either at the same frequency or at a band of frequencies. The working principle of a radio altimeter is shown in Fig1. Here two antennas are used, one for transmitting radio waves and other for receiving an echo signal reflected by ground or surface of terrains. The receiving time is a ratio of two times of altitude between craft and reflected region to light velocity in space. Generally, frequency modulated continuous wave is preferred than simple continuous wave technique [1]. Radio altimeter [1-9] is working in the band of $4.2 \mathrm{GHz}$ to $4.4 \mathrm{GHz}$ [2] and receiving frequency is differed from transmitted signal at a rate of $40 \mathrm{~Hz}$ per foot. The altimeters are also used in both civil and military aircrafts. In civil applications these are used at low visibility conditions and automatic landing systems. Civil applications altimeters give the readings up to 2,500 feet and weather altimeters give up to 60,000feet above the ground level (AGL). Military applicator altimeter is used to fly quite low over the land and the sea to avoid

DOI : 10.5121/ijwest.2012.3404 
radar detection and targeting by anti-aircraft guns or surface to air missiles.

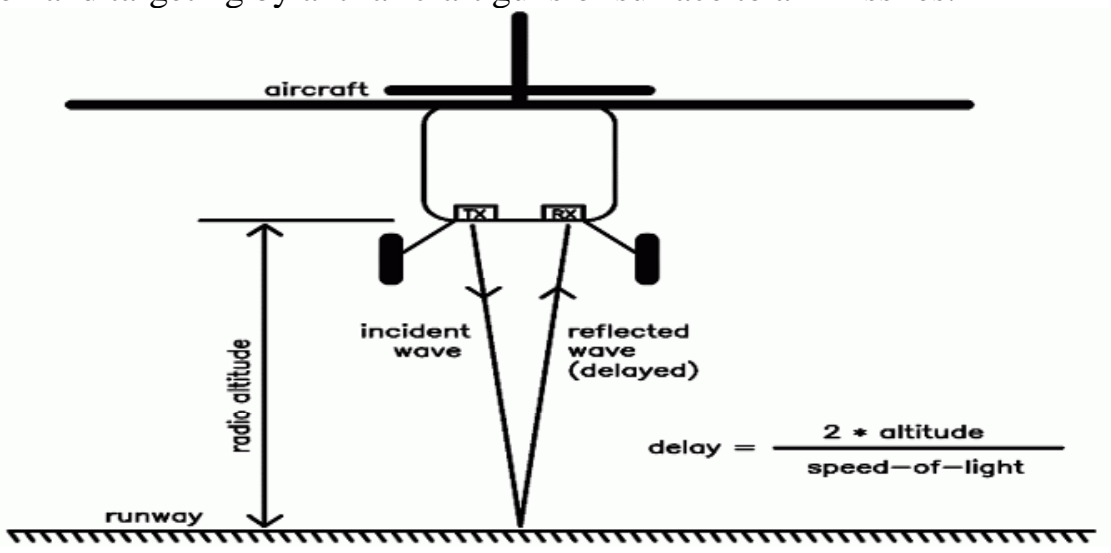

Fig: 1 Basic Conceft of Radio Altimeter

The apt antenna for radio altimeter is a microstrip antenna and also called as patch antenna [1011]. They are also used in the millimeter-wave frequency range. Microstrip patch antenna consists of a patch of metal that is on top of the grounded dielectric substrate of thickness $h$, with relative permittivity and permeability $\varepsilon_{\mathrm{r}}$ and ${ }_{\mathrm{r}}(=1)$ as shown in Fig.2a \&2b. The metallic patch may be of various shapes with rectangular, circular, and triangular etc.

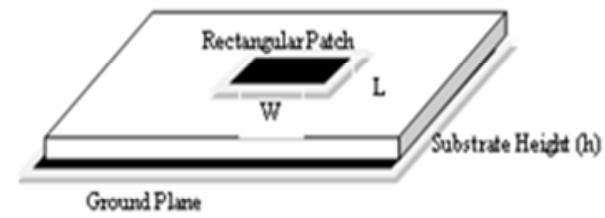

Fig, 2aRectangular Patch MicroStrip Antenna

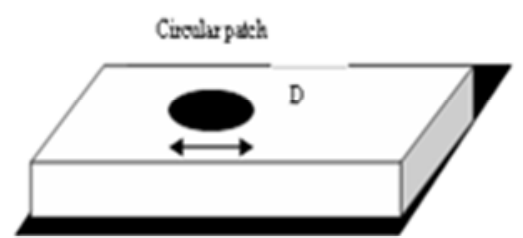

Fig. 2b Circular Patch Microstrip Antenna

The general single antennas offer low gain and low directivity. These values are not suitable for various areas like cellular, mobile, satellite communication, navigation, biomedical etc. and these parameters are to be improved. The most popular method is an array i.e., arrangement of similar patches in different structures like linear, ring, cross etc. The scientists YAGI and UDA observed and suggested the designing parameters like distance between different patches [10]. These patches are named as reflector, driven and directors. Along with these parameters the patch size can be changed for effective results. This well known method is named after these scientists as Yagi-Uda array.

Antenna array has large number of elements and has several problems if microstrip antenna elements are used. First, if each element is connected to a feed line, the resulting feeding network will introduce unwanted radiations as a result the copper losses [10-11]. Second, for phase array, each individual element will require a phase shifter in order for the beam to be steered, with result that a great number of phase shifters are needed in large arrays; the cost of the phase shifters is likely to be increased. K.F.Lee et.al[12] suggested that problem will be reduced if the array is divided in to sub arrays and feeding is given to only one patch in each of the sub array [12], with 
International Journal of Web \& Semantic Technology (IJWesT) Vol.3, No.4, October 2012

several closely spaced parasitic patches (called Reflector, and Directors) around it. The element that is directly fed is called driven element.

J.Huang [13] presented the work on rectangular patch yagi-array antenna. Parasitic patches are arranged linearly as shown in Fig.2 .He designed an antenna at $6.9 \mathrm{GHz}(\mathrm{C}$-band) and $1.58 \mathrm{GHz}$ (L band), for linear polarization. In his observations the beam tilted towards end-fire direction. He continued his work for circular polarization too. D.P.Gray, et al [17] studied on linearly polarized yagi-array at L-band $(1-2 \mathrm{GHz})$ with 4 -elements and also in S-band $(2-4 \mathrm{GHz})$ with six elements. He extended his work with different substrate materials and heights. In the later years, researchers continued the similar topic. Yang-Chang et al [14] continued their work on rectangular patch linearly polarized yagi-array antenna at $38 \mathrm{GHz}$ and observed response with different sizes and distance between elements. Chow Yen Desmond Sim et al [18] presented the work on Annularring microstrip patch for circular polarization at S-band frequency range. Garima et al [16] simulated the work on circular patch in $\mathrm{C}$-band at $6 \mathrm{GHz}$ and observed low directivity with single patch.

Krishna Kumar et.al[5], has done work on Octagonal microstrip antenna for Radar and SpaceCraft Applications. He had designed antenna in HFSS and observed results.

Before designing, the practical antenna can simulate using softwares like ANASOFT-HFSS $^{\text {TM }}$ V9.0 [23] and MATLAB. By simulation antenna characteristics can be analyzed and synthesized. These characteristics can be visualized in all dimensions Mr. M.Ben Ahmed et al., [19-24] designed a patch antenna for multi applications like GSM/PCS/UMTS/HIPERLAN for Mobile Cellular Phones in softwares. Later he tested practically and observed that both results are similar.

\section{Design Procedure}

In this paper Yagi antenna at $4.3 \mathrm{GHz}$ (C band) in linear structure with both rectangular and circular patches (Fig. 3) having linear polarization [13] is designed. Further, work was extended to different shapes [5] of patches like Square, Rhombic, Pentagon, Octagon and Edge-12 which is nearer to circular structure. All these structures are designed in ansoft HFSS simulator [23] which is working in finite discrete time domain(FDTD) and analyzed in terms of percentage impedance bandwidth and gain in $\mathrm{dB}$ on both E-Plane and H-plane.

\section{For Rectangular Patch Antenna:}

Width of the patch $\mathrm{W}=\left[\mathrm{C} / 2 * \mathrm{f}_{\mathrm{r}}\right] * \operatorname{sqrt}\left\{2 /\left(\varepsilon_{\mathrm{r}}+1\right)\right\} \quad$--- (1)

Where $\mathrm{C}$ is velocity of light in free space

$\mathrm{f}_{\mathrm{r}}$ is a resonant frequency or operating frequency

Length of the patch ' $L$ ' is generally $\lambda \mathbf{o} / \mathbf{3}<\mathrm{L}<\boldsymbol{\lambda} \mathbf{0} / \mathbf{2}$

\section{Circular Patch Antenna:}

$$
\operatorname{Radius}(a)=\frac{F}{\left.\left\{1+\frac{2 h}{\pi \varepsilon_{r} F}\left[\mid \ln \frac{\pi F}{2 h}\right]+1.7726\right]\right\}^{\frac{1}{2}}} \quad \text {-- (2) }
$$

where

$$
F=\frac{8.791}{f_{r_{\sqrt{\epsilon_{r}}}}} \times 10^{9}
$$


International Journal of Web \& Semantic Technology (IJWesT) Vol.3, No.4, October 2012

$$
\text { directivity }=\frac{41253}{\Theta_{1 d} \Theta_{\mathbf{2} d}}
$$

The percentage bandwidth [11] is calculated from return loss $\left(\mathrm{S}_{11}\right)$ graph of antenna below $10 \mathrm{~dB}$.

$\%$ Impedance bandwidth $=200 * \frac{\left(\mathrm{f}_{\mathrm{h}}-\mathrm{f}_{\mathrm{l}}\right)}{\left(\mathrm{f}_{\mathrm{h}}+\mathrm{f}_{\mathrm{l}}\right)}$

Where $f_{h}$ and $f_{l}$ are upper and lower frequency values from return loss.

The array structure shown in Fig. 3 is designed with RT-Duroid material as substrate and assumed and calculated values are given in Table-1.

\section{Table: 1}

\begin{tabular}{|l|l|}
\hline Relative Permittivity & $\boldsymbol{\varepsilon}_{\mathrm{r}}=2.2$ \\
\hline Height & $\mathrm{h}=0.1588 \mathrm{~cm}$ \\
\hline Rectangular patch as driven element & Width $(\mathrm{w})=2.7578 \mathrm{~cm}$, Length $(\mathrm{L})=2.4296 \mathrm{~cm}$ \\
\hline Circular patch as driven element & Radius ' $\mathrm{a}=1.2874 \mathrm{~cm}$ \\
\hline Reflector size & Driven Element size increased by $0.3 \mathrm{~cm}$ \\
\hline Director size & Driven Element size decreased by $0.1 \mathrm{~cm}$ \\
\hline $\begin{array}{l}\text { Distance between reflector and } \\
\text { driven element }\end{array}$ & $\mathrm{D} 10.2 \lambda$ \\
\hline $\begin{array}{l}\text { Distance between director1 and } \\
\text { driven element }\end{array}$ & $\mathrm{D} 2=0.4 \lambda$ \\
\hline $\begin{array}{l}\text { Distance between director2 and } \\
\text { director1 director3 and }\end{array}$ & $\mathrm{D} 3=0.8 \lambda$ \\
\hline $\begin{array}{l}\text { Distance between } \\
\text { director2 }\end{array}$ & $\mathrm{D} 4=0.05 \lambda$ \\
\hline $\begin{array}{l}\text { Distance between director3 and } \\
\text { director4 }\end{array}$ & $\mathrm{D} 5=0.05 \lambda$ \\
\hline
\end{tabular}

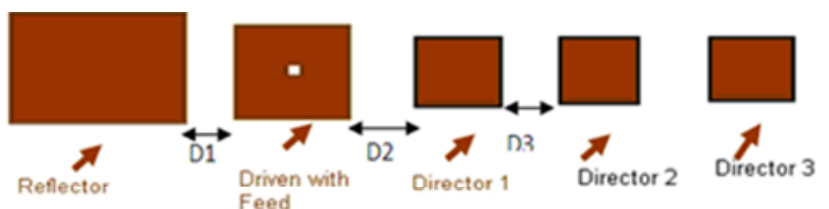

Rectangular Patch Linearly Polarized Yag-Amy Artenna

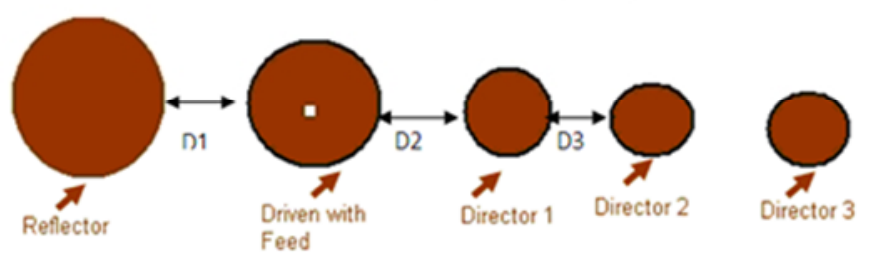

Circular Patch Linearly Polarized Yagi-Array Antenna

Fig. 3 Microstrip Array With Parasitic Elements 
International Journal of Web \& Semantic Technology (IJWesT) Vol.3, No.4, October 2012

\section{Results}

With the values obtained in section2, arrays with different combinations 2-directors (red line in Fig.6), 3-directors (green line in Fig.6), and 4-directors (blue line in Fig.6) are designed and simulated in MATLAB. The simulated values of single element are tabulated in Table-2 and pattern on E-Plane and H-Plane is shown in Fig.4.

By keeping the distance between the elements constant and varying the frequency form $1 \mathrm{GHz}$ to $20 \mathrm{GHz}$ (includes L-band, S-band, C-band, X-band, Ku-band and K-band) responses are calculated and tabulated in Table-3. From the response with 2-directors, it is observed that

- Up to $8 \mathrm{GHz}$ no side lobes are presented.

- At $4.3 \mathrm{GHz}$ the response on E-Plane of a rectangular patch array is shown in Fig.5, H-Plane is shown in Fig.7 and E-plane of circular patch array is shown in Fig.6.

- Here directivity is around $14.38 \mathrm{~dB}$ and it is higher than single patch element and beam steered is $32.65^{\circ}$ in end-fire direction.

- As frequency increased, directivity also increased and from $8 \mathrm{GHz}$ onwards side lobes are generated in circular patch array. Response at $15 \mathrm{GHz}$ is shown in Figs (8-9).

- By Keep frequency constant and vary the distances between elements and response tabulated in Table-4.

- The directivity is decreased as permittivity $\left(\varepsilon_{\mathrm{r}}\right)$ is increased and tabulated in Table-5.

- The height (h) and permittivity $\left(\varepsilon_{\mathrm{r}}\right)$ both are simultaneously changed and response is tabulated in Table-6.

- The rectangular patch array antenna at $4.3 \mathrm{GHz}$ is designed and simulated in ANSOFT-HFSS is shown in Fig.10.

- The return loss $\left(\mathrm{S}_{11}\right)$ is shown in Fig.11 represents, it resonates at two frequencies, one is at $3.93 \mathrm{GHz}$ with $-10 \mathrm{~dB}$ and second is at $7.17 \mathrm{GHz}$ with $-33 \mathrm{~dB}$.

- The directivity of an array in $\mathrm{dB}$ (shown in Fig. 12) in $\varphi=0^{\circ}$ deg plane shows $12.27 \mathrm{~dB}$ with $49.9^{0}$ tilt towards end fire direction.

- Feed tuning in rectangular patch and array is difficult than other structures like circular, 5 edges ( pentagon) and more.

- Referring to the Fig.13 the radius of a pentagon is $1.377 \mathrm{~cm}$ which is designed in ansoft HFSS .

- From Fig.14 the return loss that replicates is indicated with $\mathrm{S}_{11}$. It is tuned at the resonating frequencies $\mathrm{FR} 1=4.36 \mathrm{GHz}$ and $\mathrm{FR} 2=9.09 \mathrm{GHz}$ respectively and also called dual tuned antenna. It is suitable for both radio altimeter application and space craft applications.

- Fig. 15 implies that FR1 offers $100 \mathrm{MHz}$ bandwidth from $4.21 \mathrm{GHz}$ to $4.31 \mathrm{GHz}$ below $-10 \mathrm{~dB}$ as represented in the $S_{11}$ graph.

- It produces a gain of 7.44dB with main beam along 0 deg direction as shown in Fig.16.

- Fig.17 resembles FR2 that offers maximum gain of $6.57 \mathrm{~dB}$ and main beam is tilted with 52deg towards end- fire .

- FR2 offers a bandwidth of $730 \mathrm{MHz}$.The \% impedance bandwidth corresponding to FR2 is 7.8 as tabulated in Table 7.

- Fig.18 resembles the current distribution of the pentagon patch which is referred in Fig.13.

- Fig. 19 shows the 3D representation at FR1.Similarily the 3D representation is in Fig.20.

- The above criterion are repeated for different shapes like Rhombic, Square, Octagon, Edge-12 etc and is shown in Table-7. 
International Journal of Web \& Semantic Technology (IJWesT) Vol.3, No.4, October 2012

Table:2 Comparison between Rectangular and Circular Single Patch Antenna

\begin{tabular}{|c|c|c|c|c|}
\hline $\begin{array}{c}\text { Shape of a } \\
\text { patch }\end{array}$ & $\begin{array}{c}\text { E-plane } \\
(\text { HPBW) } \\
\text { (deg) }\end{array}$ & $\begin{array}{c}\text { H-Plane } \\
\text { (HPBW) } \\
\text { (deg) }\end{array}$ & $\begin{array}{c}\text { E-Plane } \\
\text { Directivity } \\
\text { (dB) }\end{array}$ & $\begin{array}{c}\text { H-Plane } \\
\text { Directivity } \\
\text { (dB) }\end{array}$ \\
\hline $\begin{array}{c}\text { Rectangular } \\
\text { Shape }\end{array}$ & 85 & 80 & 7.566177 & 8.092756 \\
\hline $\begin{array}{c}\text { Circular } \\
\text { Shape }\end{array}$ & 155 & 110 & 2.347921 & 5.326702 \\
\hline
\end{tabular}

Table 3: Response of an Antenna w.r.to Frequency

\begin{tabular}{|c|c|c|c|c|c|c|}
\hline \multicolumn{7}{|c|}{ Rectangular -Yagi Antenna with 2-Directors } \\
\hline $\begin{array}{l}\text { Freque } \\
\text { ncy } \\
(\mathbf{G H z})\end{array}$ & $\begin{array}{c}\text { Shift } \\
\text { angle(Til } \\
\text { t) } \\
\text { (deg) }\end{array}$ & \multicolumn{2}{|c|}{$\begin{array}{l}\text { E- } \\
\text { field } \\
\text { (dB) }\end{array}$} & $\begin{array}{c}\text { HPB } \\
\text { W } \\
\text { (deg) }\end{array}$ & \multicolumn{2}{|c|}{$\begin{array}{l}\text { Directivity } \\
\text { (dB) }\end{array}$} \\
\hline 1 & 33.29 & \multicolumn{2}{|c|}{6.604} & 41.26 & \multicolumn{2}{|c|}{13.84397} \\
\hline 2 & 33.94 & \multicolumn{2}{|c|}{6.674} & 40 & \multicolumn{2}{|c|}{14.11336} \\
\hline 3 & 33.32 & \multicolumn{2}{|c|}{6.745} & 40 & \multicolumn{2}{|c|}{14.11336} \\
\hline 3.5 & 32.06 & \multicolumn{2}{|c|}{6.767} & 40 & \multicolumn{2}{|c|}{14.11336} \\
\hline 4 & 33.29 & \multicolumn{2}{|c|}{6.809} & 38.76 & \multicolumn{2}{|c|}{14.38688} \\
\hline 4.3 & 32.65 & \multicolumn{2}{|c|}{6.824} & 38.76 & \multicolumn{2}{|c|}{14.38688} \\
\hline 6 & 33.1 & \multicolumn{2}{|c|}{6.922} & 38.76 & \multicolumn{2}{|c|}{14.38688} \\
\hline 10 & \multicolumn{2}{|l|}{31.78} & 7.094 & 37.5 & & 67393 \\
\hline 15 & 23.99 & & & 35 & & 27319 \\
\hline 25 & 17.98 & & & 30 & & .61213 \\
\hline Circula & patch-Ya & gi Ant & nna wi & with 2 & 2-Direct & \\
\hline $\begin{array}{c}\text { Freque } \\
\text { ncy } \\
(\mathbf{G H z})\end{array}$ & $\begin{array}{c}\text { Shift } \\
\text { Angl } \\
\text { e } \\
\text { (deg) }\end{array}$ & $\begin{array}{c}\text { E- } \\
\text { field } \\
\text { (dB) }\end{array}$ & $\begin{array}{l}\text { HPB } \\
\text { W } \\
\text { (deg) }\end{array}$ & & Dire & $\begin{array}{l}\text { ctivity } \\
\text { IB) }\end{array}$ \\
\hline 3.5 & 34.49 & 3.295 & 38.3 & & 14. & 8151 \\
\hline 4.3 & 35.37 & 3.903 & 38.3 & & 14. & 151 \\
\hline 5 & 34.42 & 4.366 & 38.3 & & 14. & 8151 \\
\hline 6 & 37.71 & 5.001 & 36.6 & & 14.8 & 7071 \\
\hline 8 & 27.09 & 5.994 & 31.66 & & 16.144 & $\begin{array}{c}\text { SLL }=1 . \\
277\end{array}$ \\
\hline 10 & 25.91 & 6.774 & 31.6 & & & 144 \\
\hline 15 & 24.49 & 7.717 & 25 & & 18.195 & $\begin{array}{c}\text { SLL=3. } \\
057\end{array}$ \\
\hline 20 & 36.57 & 7.524 & 21.66 & & 19.441 & $\begin{array}{c}\text { SLL }=0 . \\
863\end{array}$ \\
\hline
\end{tabular}


International Journal of Web \& Semantic Technology (IJWesT) Vol.3, No.4, October 2012

Table 4: Response of an Antenna w.r.to distance between elements

\begin{tabular}{|l|c|c|c|c|}
\hline $\begin{array}{c}\text { Distance } \\
(\lambda)\end{array}$ & $\begin{array}{c}\text { Tilt } \\
(\mathrm{deg})\end{array}$ & $\mathrm{E}(\mathrm{dB})$ & $\begin{array}{c}\text { HPBW } \\
(\mathrm{deg})\end{array}$ & $\begin{array}{c}\text { Directivity } \\
(\mathrm{dB})\end{array}$ \\
\hline $\begin{array}{c}\text { Distance between Reflector and Driven Element } \\
(\mathrm{D} 1)\end{array}$ \\
\hline 0.1 & 31.31 & 4.664 & 20 & 14.11336 \\
\hline 0.2 & 32.65 & 6.824 & 19.38 & 14.38688 \\
\hline 0.3 & 33.88 & 7.891 & 19.38 & 14.38688 \\
\hline \multicolumn{5}{|l|}{} \\
\hline $\begin{array}{l}\text { Distance between Director and Driven Element } \\
\text { D3( } \lambda)\end{array}$ & \multicolumn{5}{|l}{} \\
\hline $\begin{array}{l}0.3, \\
0.8\end{array}$ & 35.8 & 7.701 & 57.5 & 10.9612 \\
\hline $\begin{array}{l}0.4, \\
0.8\end{array}$ & 37.13 & 1.875 & 38.76 & 14.38688 \\
\hline
\end{tabular}

Table 5: Response of an Antenna w.r.to SUBSTRATE $\left(\varepsilon_{\mathrm{r}}\right)$ Rectangular patch -Yagi Antenna with 2-Directors, $\mathrm{h}=0.1588 \mathrm{~cm}$

\begin{tabular}{|c|c|c|c|c|c|}
\hline $\begin{array}{c}\text { Frequency } \\
(\mathrm{GHz})\end{array}$ & $\varepsilon_{\mathrm{r}}$ & $\begin{array}{c}\text { Tilt } \\
(\mathrm{deg})\end{array}$ & $\begin{array}{c}\mathrm{E} \\
(\mathrm{dB})\end{array}$ & $\begin{array}{c}\text { HPBW } \\
(\mathrm{deg})\end{array}$ & $\begin{array}{c}\text { Directivity } \\
(\mathrm{dB})\end{array}$ \\
\hline 4.3 & 2.2 & 32.65 & 6.824 & 38.76 & 14.38688 \\
\hline 4.3 & 2.34 & 33.1 & 6.62 & 38.76 & 14.38688 \\
\hline 4.3 & 3.5 & 32.79 & 5.282 & 42.5 & 13.58678 \\
\hline 4.3 & 4.4 & 31.1 & 4.629 & 47.5 & 12.62068 \\
\hline 4.3 & 6.15 & 31.09 & 3.997 & 86.26 & 7.438366 \\
\hline 4.3 & 10.2 & 30.83 & 3.93 & 103.76 & 5.833956 \\
\hline Circular patch -Yagi Antenna with 2-Directors \\
\hline $\begin{array}{c}\text { Frequency } \\
(\mathrm{GHz})\end{array}$ & $\varepsilon_{\mathrm{r}}$ & $\begin{array}{c}\text { Tilt } \\
(\mathrm{deg})\end{array}$ & $\begin{array}{c}\mathrm{E} \\
(\mathrm{dB})\end{array}$ & $\begin{array}{c}\text { HPBW } \\
(\mathrm{deg})\end{array}$ & $\begin{array}{c}\text { Directivity } \\
(\mathrm{dB})\end{array}$ \\
\hline 4.3 & 2.2 & 32.65 & 6.824 & 38.76 & 14.38688 \\
\hline 4.3 & 2.34 & 35.71 & 3.702 & 38.34 & 14.48151 \\
\hline 4.3 & 3.5 & 33.07 & 2.592 & 51.66 & 11.89147 \\
\hline 4.3 & 4.4 & 33.27 & 2.103 & 51.66 & 11.89147 \\
\hline 4.3 & 10.2 & 32.73 & 1.25 & 110 & 5.326702 \\
\hline
\end{tabular}


International Journal of Web \& Semantic Technology (IJWesT) Vol.3, No.4, October 2012

Table 6: Response of an Antenna w.r.to Substrate and Height

\begin{tabular}{|c|c|c|c|c|c|}
\hline \multicolumn{6}{|c|}{$\begin{array}{l}\text { Rectangular-Patch Yagi with different Heights and } \varepsilon_{x} \text { at } \\
\text { Frequency } 4.3 \mathrm{GHz}\end{array}$} \\
\hline$\varepsilon$ & $\begin{array}{l}\text { Height } \\
(\mathrm{cm})\end{array}$ & $\begin{array}{c}\text { Tilt } \\
\text { (deg) }\end{array}$ & $\begin{array}{c}E \\
(\mathrm{~dB})\end{array}$ & $\begin{array}{c}\text { HPB } \\
\text { W } \\
(\mathrm{deg})\end{array}$ & Directivity $(\mathrm{dB})$ \\
\hline 2.2 & 0.0794 & 32.88 & 6.829 & 40 & 14.113 \\
\hline 2.2 & 0.1588 & 32.65 & 6.824 & 38.7 & 14.386 \\
\hline 2.2 & 0.3176 & 32.7 & 6.898 & 37.5 & 14.673 \\
\hline 2.2 & 0.6352 & 35.06 & 6.713 & 35 & 15.273 \\
\hline 3.5 & 0.6352 & 36.9 & 5.189 & 37.5 & 14.673 \\
\hline 6.15 & 0.6352 & 31.9 & 3.912 & 53.7 & 11.545 \\
\hline \multicolumn{6}{|c|}{ Circular-patch Yagi } \\
\hline 2.2 & 0.0794 & 34.5 & 3.885 & 38.3 & 14.481 \\
\hline 2.2 & 0.3176 & 35.45 & 3.933 & 38.3 & 14.481 \\
\hline 2.2 & 0.6352 & 35.6 & 3.987 & 38.3 & 14.481 \\
\hline 3.5 & 0.6352 & 32.29 & 2.623 & 51.6 & 11.891 \\
\hline 10.2 & 0.6352 & 31.9 & 1.255 & 88.3 & 7.2314 \\
\hline
\end{tabular}

Table: 7 Response of different Shapes of patch antenna

\begin{tabular}{|c|c|c|c|c|c|}
\hline $\begin{array}{c}\text { Name of an antenna } \\
\text { Structure }\end{array}$ & $\begin{array}{c}\text { Impedance } \\
\text { Band } \\
\text { Width(\%) }\end{array}$ & $\begin{array}{c}\text { FR1 } \\
(\mathbf{G H z})\end{array}$ & $\begin{array}{c}\text { Gain } \\
(\mathbf{D B})\end{array}$ & $\begin{array}{c}\text { FR2 } \\
\mathbf{( G H z )}\end{array}$ & $\begin{array}{c}\text { Gain } \\
\text { (DB) }\end{array}$ \\
\hline Rectangle & 1.72 & 3.82 & 6.94 & ---- & --- \\
\hline Square & 5.1 & 3.91 & 6.823 & 7.73 & 5.89 \\
\hline Circle & 8.84 & 4.39 & 7.355 & 9.27 & 5.58 \\
\hline Rhombic & 5.81 & 4.62 & 7.63 & 9.19 & 4.87 \\
\hline Pentogon & 7.8 & 4.36 & 7.44 & 9.09 & 6.57 \\
\hline Octagon & 6.89 & 4.03 & 7.05 & 8.64 & 5.07 \\
\hline Edges12 & 5.45 & 4.09 & 7.10 & 8.36 & 4.31 \\
\hline
\end{tabular}

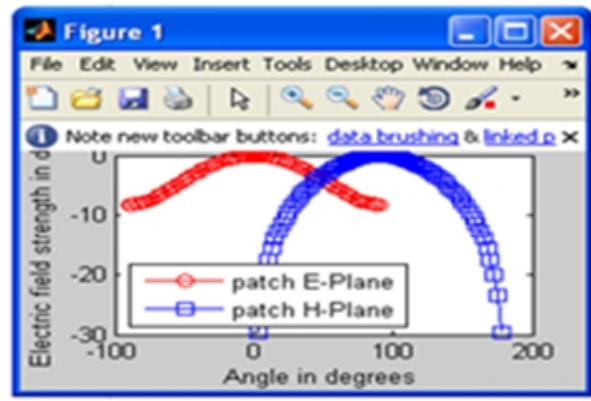

Fig 4 Radiation Pattern of Rectangular patch at $4.3 \mathrm{GHz}$ on $\mathrm{E}$-Plane and $\mathrm{H}$-Plane

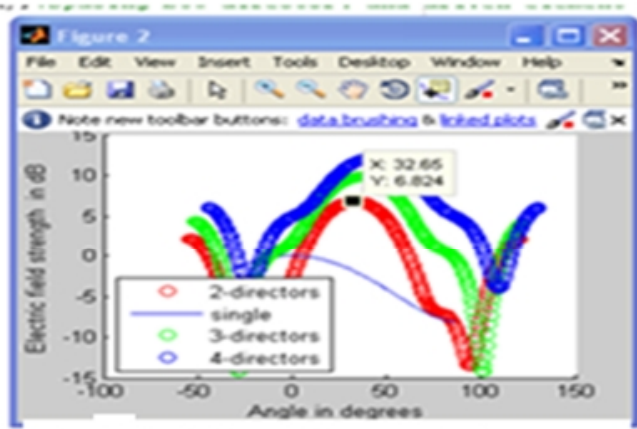

Fig 5 Radiation Pattern of Rectangul ar patch Array at 4. $3 \mathrm{GHz}$ E-Plane 
International Journal of Web \& Semantic Technology (IJWesT) Vol.3, No.4, October 2012

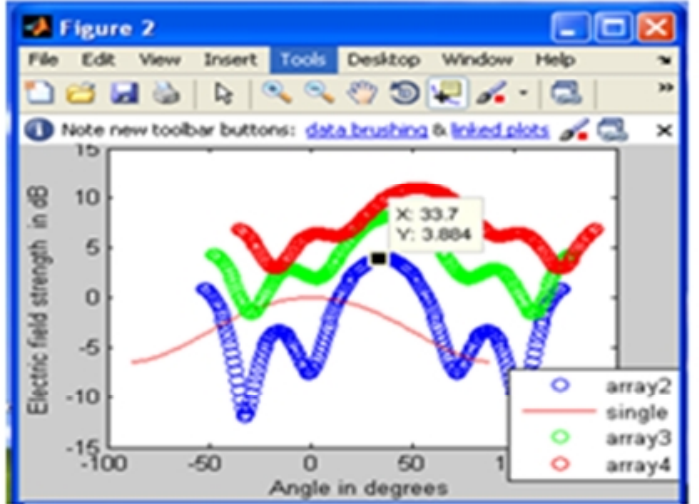

Fig. 6 Radiation Pattern of Orcular patch Array at $4.3 \mathrm{GHz}$ E-Plane
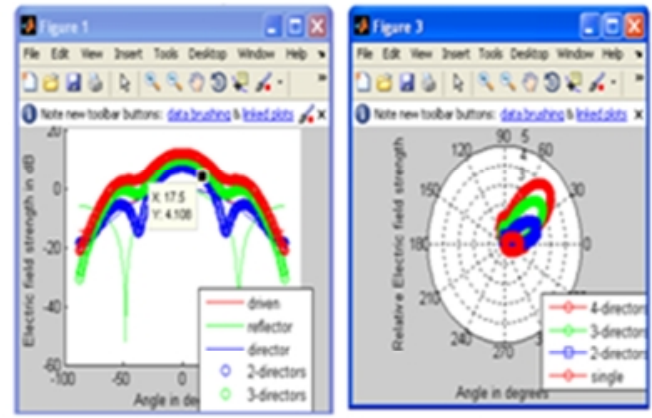

Fig,8 Radiation Pattern of Rectangular patch Array at $15 \mathrm{GHz}$ on E-Plane

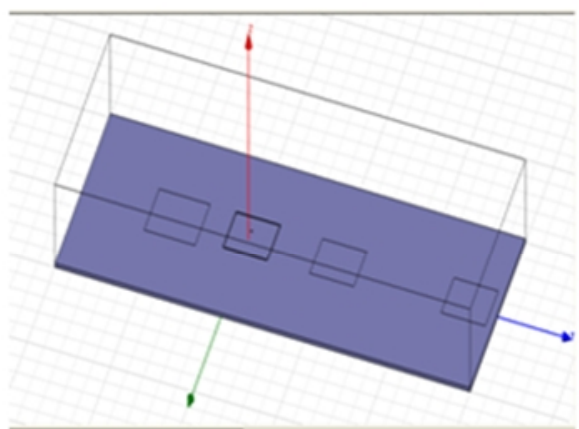

Fig10 Rectangular patch 4-Element Yagi-Array design in Anasoft-HFSS

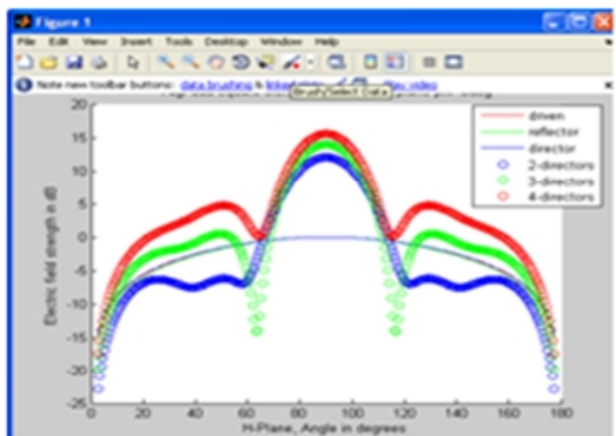

Fig 7 Radiation Pattern of Rectangular patch Array at $4.3 \mathrm{GHz}$ on $\mathrm{H}$-Plane

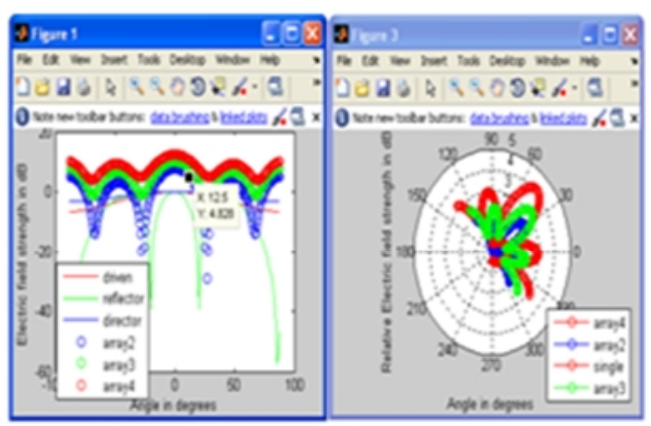

Fig9 Radiation Pattern of Circular patch Array at $15 \mathrm{GHz}$ on E-Plane

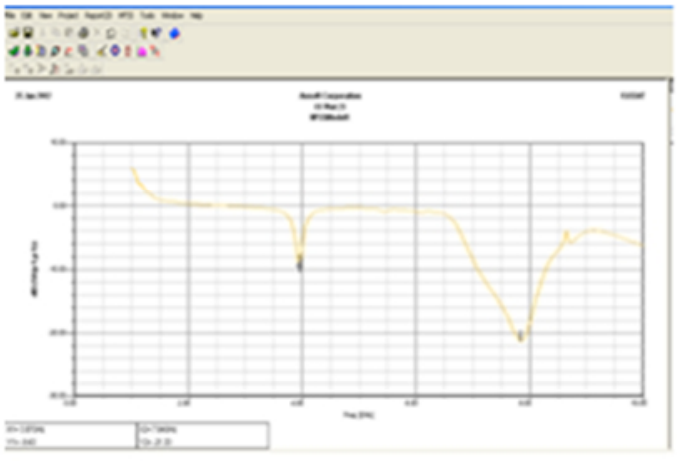

Fig. 11 Return loss $S_{11}$ (dB) of Rectangular patch Array 
International Journal of Web \& Semantic Technology (IJWesT) Vol.3, No.4, October 2012

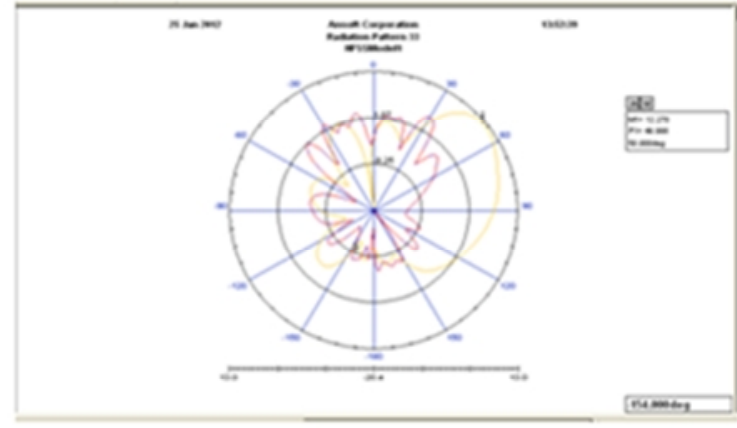

Fig 12 Directivity of rectangular patch Array at $3.93 \mathrm{GHz}$ in $\varphi=0^{\circ}$ plane

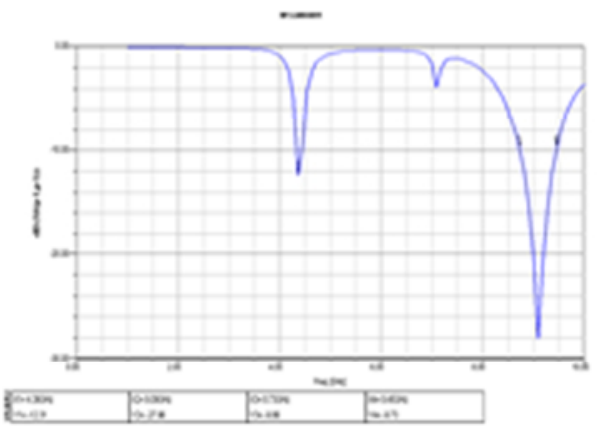

Fig:14 retum loss $\mathrm{S}_{11}(\mathrm{~dB})$ of Pentagon Microstrip Antenna in Ansoft HFSS (1 GHz-10GHz)

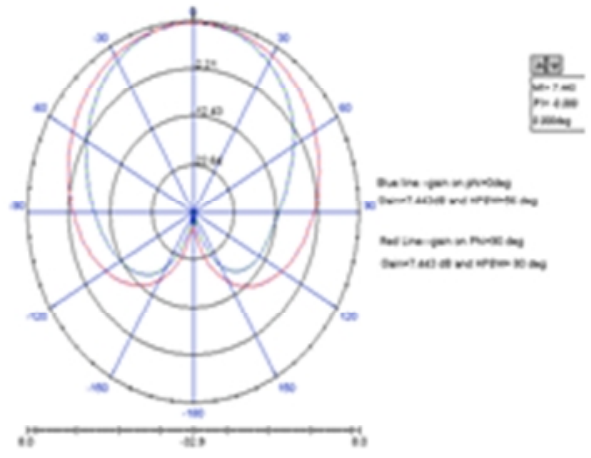

Fig:16 Radiation pattem of Pentagon Microstrip Antenna at $4.36 \mathrm{GHz}$

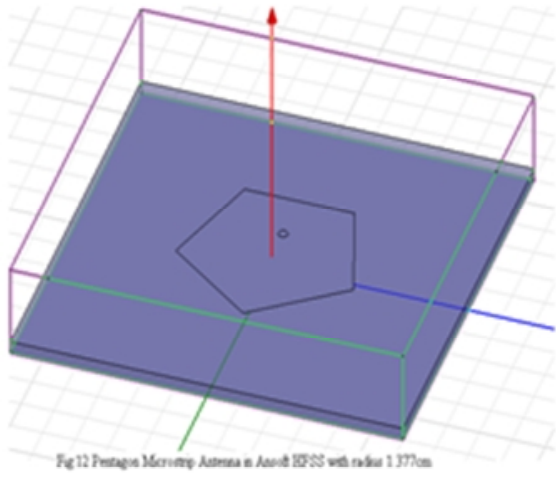

Fig:13 Pentagon Microstrip Antenna in Anseft HFSS with radius $1.377 \mathrm{~cm}$

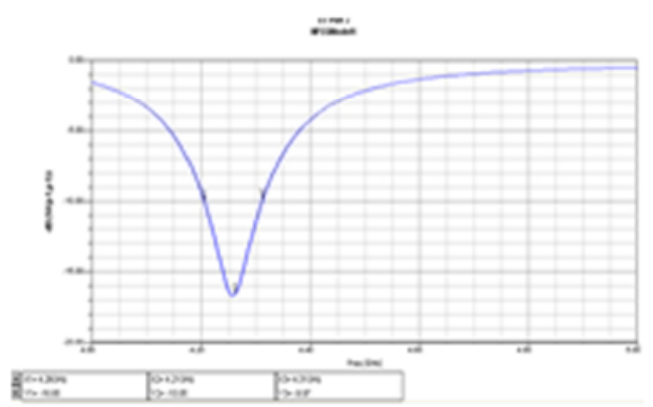

Fig: 15 Retum Loss $\mathrm{S}_{11}(\mathrm{~dB})$ of Pentagon Microstrip Antenna ( $4 \mathrm{GHz}-5 \mathrm{GHz})$

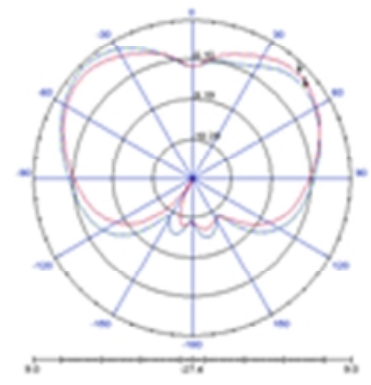

$\frac{5}{20}$

Fig:17. Radiation pattem of Pentagon Microstrip Antenna at $9.09 \mathrm{GHz}$ 


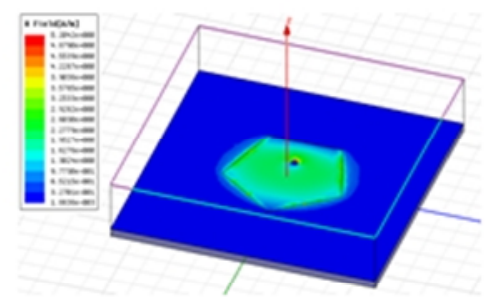

Fig:18 Current distribution on Pentagon Microstrip Antenna at $4.36 \mathrm{GHz}$
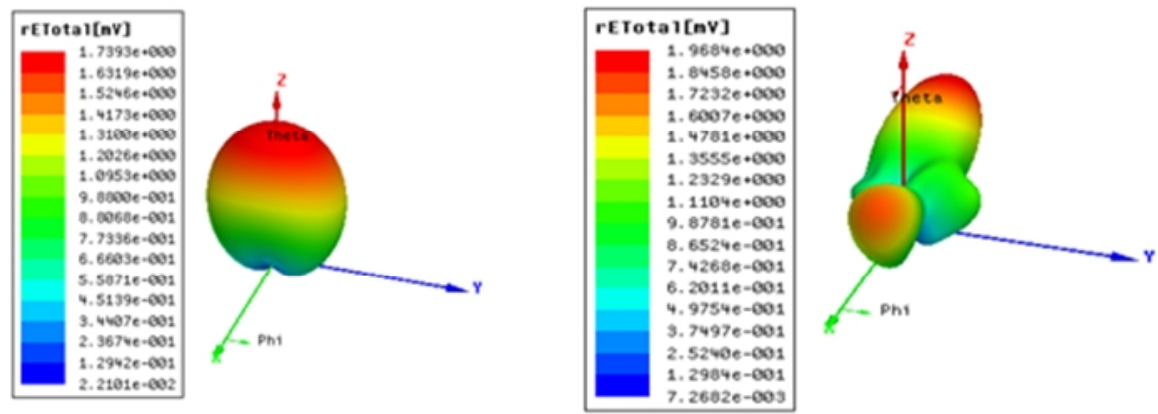

Fig:19 3D Radiation pattem of Pentagon Microstrip Antenna at $4.36 \mathrm{GHz}$

Fig:2Q 3D Radiation pattem of Pentagon Microstrip Antenna at $9.09 \mathrm{GHz}$

\section{Conclusion}

The design of rectangular patch Yagi antenna and circular patch Yagi antenna that operates at linear polarization has been done using MATLAB, ANSOFT-HFSS software. Calculations show that area of a circular patch is less than area of a rectangular patch. The antennas were simulated in MATLAB and results are tabulated. Results (Table 2) shows the comparison that circular patch Yagi antenna radiates electric field towards broadside than rectangular patch and it offers high directivity for frequency above $15 \mathrm{GHz}$, around $3 \mathrm{~dB}$ even though it has side lobes. The effect of different distances between reflector and driven element is almost negligible (from Table 3). In both the arrays, the performance is degraded due to high values of relative permittivity $\varepsilon_{\mathrm{r}}$ (from Table 4) and the effect of substrate on the result is very less at low relative permittivity $\varepsilon_{\mathrm{r}}$ (from Table 5). Finally rectangular patch yagi-array designed in Anasoft HFSS and compared with MATLAB results and observed $2 \mathrm{~dB}$ difference. Referring to the Table 7 it is proved that both the pentagon \& circle shapes acts as a perfect choice in the design of radio altimeter. This design offers dual resonant frequency band with is exactly not available with the rectangular structure. With this innovative step there is an increase in the probability of utilization of the other structures of radio altimeter. This work can be extended for different Yagi designs for circular polarization at different frequencies for different applications.

\section{References}

1. Leo G. Maloratsky, “An Aircraft Single-antenna FM Radio Altimeter”, Microwave Journal, ISSN 01926225, May 2003.

2. Merrill I. Skolnik, "Introduction to Radar Systems", Tata McGRAW Hill, Second Edition, pp. 84-86. 
International Journal of Web \& Semantic Technology (IJWesT) Vol.3, No.4, October 2012

3. Radio Altitude, "The Instrument of Choice" Cygnus Interactive.

4. J. L. Volakis, "Antenna Engineering Handbook", 4th ed. New York: McGraw Hill, 2007.

5. Krishna Kumar, Er. Sukhdeep Kaur, "Investigation on Octagonal microstrip antenna For Radar and Space-Craft Applications", International Journal of Scientific \& Engineering Reasearch, Volume-2, Issue 11, (Nov-2011).

6. Baltsavias, E.P. "Airborne laser scanning: basic relations and formulas", ISPRS Journal of Photogrammetry and Remote Sensing, 54, 199-214, 1999.

7. Bamber, J.L., Ekholm, S. and Krabill, W.B., "The accuracy of satellite radar altimeter data over the Greenland ice sheet determined from airborne laser data", Geophysical Research Letters., v. 25, p. 3177-3180,1998.

8. Ekholm, S. Bamber, J.L., and Krabill, W. B. ,"The use of airborne laser data to calibrate satellite radar altimetry data over ice sheets", Journal of Geodynamics. 34, 377-390, 2002.

9. Wehr, A. and Lohr, U., Airborne laser scanning - an introduction and overview. ISPRS Journal of Photogrammetry and Remote Sensing, 54, 68-82, 1999.

10. Balanis C.A, "Antenna Theory: Analysis and Design", $2^{\text {nd }}$ Edition, John Wiley and Sons, NewYork.

11. Ramesh Garg, Prakash Bhartia, InderBh al, Apisak Ittipiboon, "Microstrip Antenna Design HandBook" , Artech House, Inc.,2001.

12. K. F. Lee, et al., "Micro strip Antenna Array with Parasitic Elements" IEEE AP-S Symposium Digest, , pp. 794-797, June 1987.

13. J. Huang, "Planar Microstrip Yagi Array Antenna", IEEE Trans. on Antennas and Propag., pp. 894-897, Feb.1989.

14. Yang-Chang et al., "Design of a $38 \mathrm{GHz}$ Printed Yagi Antenna with Multiple Directors", IEEE Trans. on Antennas and Propag. pp. 606-609, Jan. 2001.

15. M. Haneishi, et al., "Beam-Shaping of Micro strip Antenna by Parasitic Elements having Coaxial Stub," Trans. IECE of Japan, vol. 69-B, pp. 1160-1161,1986.

16. Garima, et al.,"Broadband Circular Patch Microstrip antenna with Diamond Shape Slot for Space Communication" International Conference on Emerging trends in Electronic and Photonic Devices \& Systems, pp. 332-335,

ELECTRO-2009.

17. D.P.Gray et al., "Xperimental Study of Parasitically Steered, Fixed Beam Microstrip Patch Arrays", IEEE Trans. on Antennas and Propag., pp. 1276-1279, March1997.

18. Chow Yen Desmond Sim et al., () "Design of an annular Ring Microstrip Antenna for Circular Polarization" IEEE Trans. on Antennas and Propag. pp. 471-474, Aug.2004.

19. M.Ben Ahmed et al., "GSM/PCS/UMTS/HIPERLAN for Mobile Cellular Phones", European Journal of Scientific Research,Vol.32 No.2, pp.151-157, 2009.

20. T.Durga Prasad et al., "Comparisons of Circular and Rectangular Microstrip Patch Antennas", International Journal of Communication Engineering Applications, Vol 2, issue 4, pp.187-197, July 2011.

21. Shi-wei Qu et al,'High- Efficiency periodic sparse patch array based on Mutual coupling”, Antennas and wireless propagation Letters, IEEE, pp.1317-1320, vol.10, 2011.

22. A. A. Eldek, A. Z. Elsherbeni, and C. E. Smith, "Microstrip-fed printed lotus antenna for wideband wireless communication system," IEEE Antennas Propag. Mag., vol. 46, no. 6, pp. 164-173, Dec. 2004.

23. Ansoft Corporations, Designer and High Frequency Structure Simulator (HFSS) [Online]. Available: www.ansoft.com

24. Sunil Kumar, Rajgopal and Satish Kumar Sharma,"Investigation on UWB Pentagon Shape Microstrip Slot Antenna for Wireless Communications" IEEE Transactions on Antenna And Propagation, Vol. 57, No.5,May 2009. 